\title{
Pattern recognition of grazing dynamics in response to fish removal (Lake Wolderwijd, Netherlands) using non-supervised artificial neural networks
}

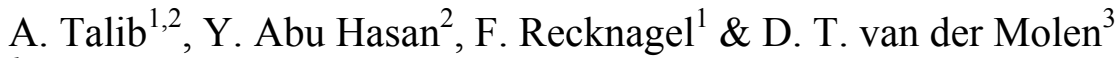

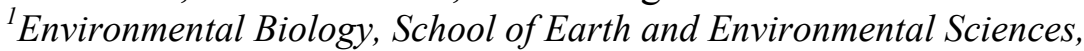 \\ University of Adelaide, Australia \\ ${ }^{2}$ Universiti Sains Malaysia, Minden, Malaysia \\ ${ }^{3}$ Institute of Inland Water Management, The Netherlands
}

\begin{abstract}
Limnological time-series data sets of the eutrophic Dutch lake Wolderwijd were modelled by means of non-supervised artificial neural networks (NSANN) for pattern recognition. This lake has been subjected to various eutrophication control measures for the past 3 decades, including the top-down approach of planktivorous fish removal or biomanipulation. NSANN was applied for patternising the effects of pre- and post-fish removal on the phyto- and zooplankton dynamics. Results of the study have demonstrated that NSANN can: (1) elucidate short-term shifts and long-term causal relationships of complex ecological dynamics, associated with grazing, taking into account the ongoing impacts of phosphorus removal in the lake, (2) illustrate the potential impact of zooplankton grazing during the clear-water phase in spring and (3) the complex dynamics involving water quality, phyto- and zooplankton changes that take place when Daphnia peaks

Keywords: non-supervised ANN, biomanipulation, phytoplankton, zooplankton, grazing, planktivorous fish.
\end{abstract}

\section{Introduction}

Exploiting Daphnia to control eutrophication is dependent on increased predation on planktivorous fishes by increasing piscivorous fish-stocks. This is a top-down approach based on the trophic cascades (Carpenter et al. [1]) for 
eutrophication control, also known as biomanipulation or food-web manipulation. Fish removal and commercial fishing can also contribute to biomanipulation by harvesting of planktivorous fish, in particular. Biomanipulation has been widely studied and demonstrated in combination with bottom-up eutrophication control to be effective for restoring eutrophication problems in shallow lakes (Jeppesen et al. [2]; Moss et al. [3]; Hosper [4]; Benndorf [5]).

Much research has been carried out to understand biomanipulation. Some of the difficulties of understanding biomanipulation are related to the complexities of the foodweb itself as reviewed by Crowder et al. [6]. Species may change its trophic level and the diet of fish may change with niche selection. A predator may influence other trophic levels and there may be simultaneous direct or indirect interactions with reducing predation either on the plankton or benthos. Changing the structure of food chain may have secondary and confounding effects. Other indirect and direct effects of fish involve underwater light climate and vegetation development. One indirect effect of benthivorous fish is an increase in turbidity due to increased resuspension of sediment. Jeppesen et al. [7] argued that macrophyte refuge effect for large bodied zooplankton is higher in vegetation rich lakes compared to mesotrophic lakes and there is no proof to date that higher zooplankton to phytoplankton ratio in clear water lakes are due to grazer control.

In Lake Wolderwijd, biomanipulation was implemented in winter 1990-1991, with removal of $157.4 \mathrm{~kg}$ hectare $^{-1}$ fish while $45.6 \mathrm{~kg}$ hectare ${ }^{-1}$ remained. Measurements in June to September 1991 showed that fish biomass had increased to $115 \mathrm{~kg}$ hectare ${ }^{-1}$. The estimated fish stock in 1980 's i.e. before biomanipulation is approximately between 203 to $300 \mathrm{~kg}$ fresh weight in 1981 and 1987 respectively (van der Molen and Boers [8]). The central question that surrounds the effectiveness of biomanipulation is grazing. Has the abundance of Daphnia and other herbivorous zooplankton increased after biomanipulation? Is there a shift in the plankton communities with an increase in Daphnia or other grazers? These key questions include the role of the cladocerans for example Daphnia and Bosmina. These questions are posed assuming that the phyto- and zooplankton dynamics reflect the top-down "cascading effects" (Carpenter et al. [1]) of the biomanipulation process. Before biomanipulation was implemented, from 1980 onwards, Lake Wolderwijd was flushed with polder water low in $\mathrm{P}$ and high in $\mathrm{N}$ and $\mathrm{Ca}$, turning it from $\mathrm{N}$ to P-limitation. Flushing was increased from 1 to 2 million $\mathrm{m}^{3}$ per month in 1988-1989 and from 4 to 7 million $\mathrm{m}^{3}$ per month during 1991-1992 which reduced the water residence time to 6 months (Gulati and van Donk [9]). Although biomanipulation produced the desired results in some cases (Benndorf [5]), water managers still need models for pattern recognition and to improve causal understanding of the biomanipulated system. The application of computational modelling techniques such as NSANN for pattern analysis (Recknagel et al. [10]) can improve understanding of ecological dynamics of lakes. In this study, we query the possibility of "grazing induced clear-water phase" in Lake Wolderwijd as a result of biomanipulation with ongoing flushing. 


\subsection{Lake Wolderwijd}

Lake Wolderwijd was created in 1965 (see Figure 1). This lake is connected to Lake Nuldernauw at the edge of the Veluwemeer region. The creation of these lakes involved the empoldering of Flevoland. Lake Wolderwijd has a surface area of 1918 hectares with a mean depth of $1.5 \mathrm{~m}$. It has an open connection to Lake Nuldernauw that has a surface area of 6.97 hectares and a mean depth of $1.65 \mathrm{~m}$. Occasionally large amounts of water are flushed through the lake from Lake Veluwemeer, where the use of phosphate-free detergents and restoration measures were carried out (van der Molen [11]). Therefore the phosphorus concentration in the incoming water is decreased and this caused a slight decrease in phosphate, nitrogen and chlorophyll-a (Chl-a) concentration. Eutrophication slowly occurred from 1970 onwards. The water quality in the lake continued to decline and by 1981 it was considered as progressively hypertrophic with a complete dominance of cyanobacteria. From November 1990 to July 1991, a large food web manipulation was carried out whereby $75 \%$ of bream biomass was removed and young pike introduced. At the same period of time, blue-green algae was less abundant, peaking at approximately $50 \%$. In 1991, there was a clear water phase with Secchi depth measurements of $1 \mathrm{~m}$ for six weeks. The hydraulic load was increased to $108.10^{6} \mathrm{~m}^{3}$ per year by 1992 , and this was followed by two weeks of clear water phase. By the years 1996 and 1997, the water quality declined again (van der Molen [11]).

\section{Data and modelling techniques}

A total of 4 years data were available for NSANN (Table 1). Due to zooplankton data limitation from no sampling in some months, we used 9 months of daily interpolated data (April to October).

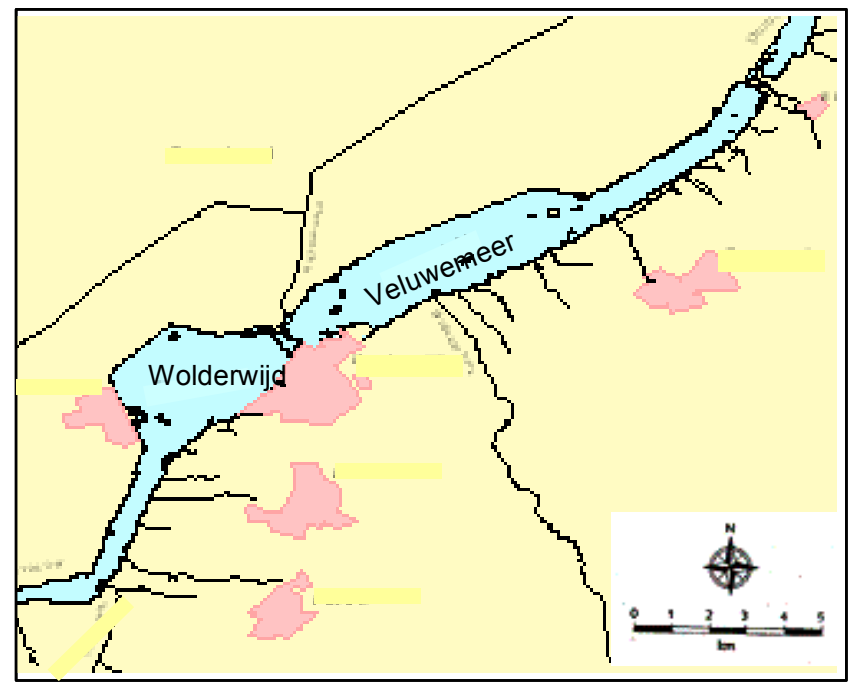

Figure 1: Locations of Lake Wolderwijd in central Netherlands. 
Table 1: $\quad$ Limnological variables of Lake Wolderwijd.

\begin{tabular}{|l|l|}
\hline \multicolumn{2}{|c|}{$\begin{array}{c}\text { Lake Wolderwijd } \\
(1989-1990:\end{array}$} \\
\hline Limnological variables & Mean/Min/Max \\
\hline Nitrate $\mathrm{NO}_{3}$-N mg/l & $0.11 / 0.05 / 0.2$ \\
\hline Phosphate $\mathrm{PO}_{4}$-P & $0.007 / 0.001 / 0.03$ \\
\hline Secchi Depth m & $0.37 / 0.15 / 0.9$ \\
\hline $\mathrm{pH}$ & $8.5 / 8.0 / 8.8$ \\
\hline Blue-green Algae $\mathrm{mm}^{3} / 1$ & $108.7 / 0 / 8.8$ \\
\hline Green Algae $\mathrm{mm}^{3} / 1$ & $5.3 / 0.44 / 17.59$ \\
\hline Diatom $\mathrm{mm}^{3} / 1$ & $7.94 / 0 / 51.15$ \\
\hline Oscillatoria cells/ml $/ \mathrm{ml}^{2}$ & $27164 / 0 / 58050$ \\
\hline Scenedesmus cells/ml & $1533 / 0 / 518$ \\
\hline Cladocera ind/ml & $80.7 / 0 / 518$ \\
\hline Copepode ind $/ \mathrm{ml}$ & $102.1 / 3 / 848$ \\
\hline Cyclopoidea ind/ml & $98.1 / 3 / 848$ \\
\hline Daphnia ind $/ \mathrm{ml}$ & $52.4 / 0 / 418.6$ \\
\hline Bosmina ind $/ \mathrm{ml}$ & $20.9 / 0 / 205$ \\
\hline
\end{tabular}

Table 2: $\quad$ Top-down management periods of Lake Wolderwijd.

\begin{tabular}{|l|l|}
\hline Eutrophication Control & Lake Wolderwijd \\
\hline Pre- Biomanipulation & $1989-1990$ \\
\hline Post-Biomanipulation & $1992-1993$ \\
\hline
\end{tabular}

\subsection{NSANN design and training}

The concept of NSANN was introduced by Kohonen [12]. This was applied to ordination, clustering and mapping of the lake data sets in relation to bi-monthly data and water quality conditions according to Kohonen [13]. NSANN was trained using normalised input data and the Euclidian distances between the inputs are calculated and visualised as a distance matrix (U-matrix), and as a partition map (K-means). Dissimilar input patterns map onto different regions of the input space, while similar patterns are clustered to groups. The aim is to patternise the phyto- and zooplankton data sets in relation to pre- and post- fish removal period according to Table 2 . Figure 2 shows the bi-monthly clusters for the Lake Wolderwijd as mapped by the U-matrix and the K-means method using the SOM Toolbox of MATLAB 5.3 (Vesanto [14]). Rough clusters of the colour-coded U-matrix are shown (Figure 2a) where the light areas denote the clusters and the dark areas separate each clusters.

The middle-left cluster of the U-matrix is identified as April-May, the bottom-left cluster May-June, the mid-right cluster relates to June-July, the topright cluster relates to July-August and top-middle cluster to August-September. The U-matrix identified an anticlockwise transition of the months with marginal overlapping areas at the borders of the clusters. The plane quality was quite high with a quantization error of 0.644 and a topographic error of 0.023 . 


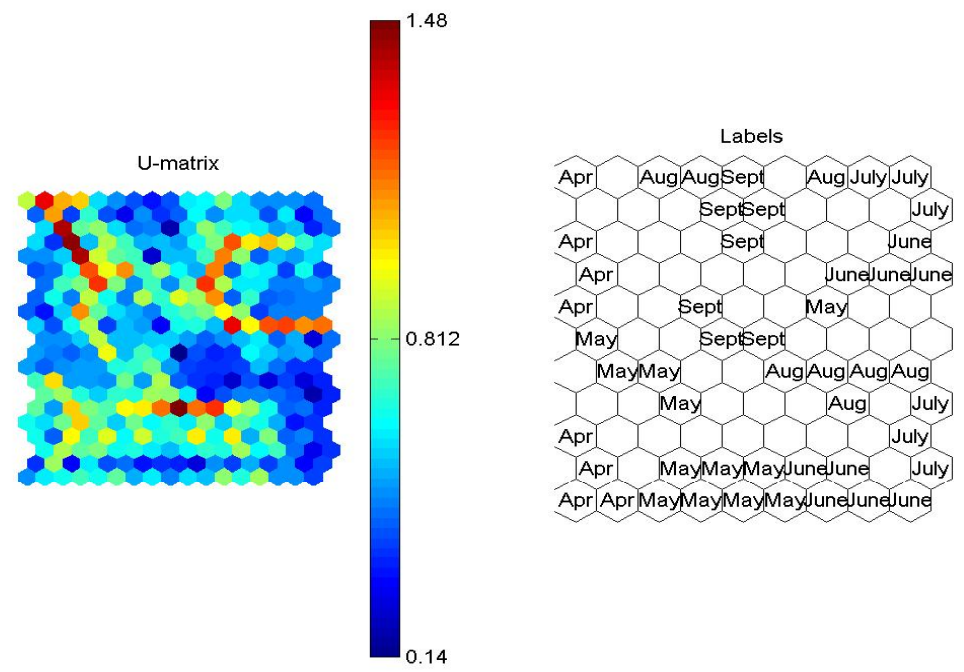

(a)

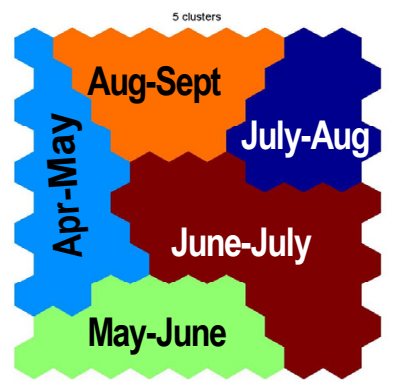

(b)

Figure 2: $\quad$ NSANN clusters represented as distance matrix map (U-matrix) of months (a) and partitioned map (K-means) of bi-monthly clusters (b).

\section{Results and discussion}

\subsection{Phyto- and zooplankton individual species dynamics}

The hypotheses tested are that phyto- and zooplankton individual species exhibit short-term seasonal patterns that relate to nutrients, $\mathrm{pH}$ and Secchi depths, with higher $\mathrm{pH}$, decreased light attenuation and higher abundances of edible phytoplankton before fish removal compared to lowered $\mathrm{pH}$, increased light attenuation and increased zooplankton grazing after fish removal. The NSANN results showed that the phyto- and zooplankton individual species (see Figure 3) 
changed seasonally in relation to nutrients, water transparency and $\mathrm{pH}$ values. Prior to biomanipulation period, in 1989 to 1990, the water was clear in May to June following a period of high $\mathrm{NO}_{3}-\mathrm{N}$ in April to May with maximal $\mathrm{pH}$ in June to July. Scenedesmus and Daphnia were dominant during July to August while Bosmina peaked in May to June (during the clear-water phases). Oscillatoria is in the warmer months of July to September with moderate abundance from June. This is associated with increased $\mathrm{PO}_{4}-\mathrm{P}$ and $\mathrm{pH}$ during this period. Algae thrive under high $\mathrm{PO}_{4}-\mathrm{P}$ conditions (Reynolds [15]). Blue-green algae generally shows negative response to $\mathrm{pH}<6$, but thrive well under neutral or alkaline conditions (Paerl [16] cited Shapiro [17]). With intensified flushing and biomanipulation, there is a shift in the seasonality of the above variables with clear-water phases in July to August (correspond to maximal Secchi depth). Scenedesmus peaked in April to May while Oscillatoria is highest between May to July. Bosmina peaked in May to June with increasing abundance in August to September. Daphnia has shifted to dominance in May to June in relation to a peak in Scenedesmus from
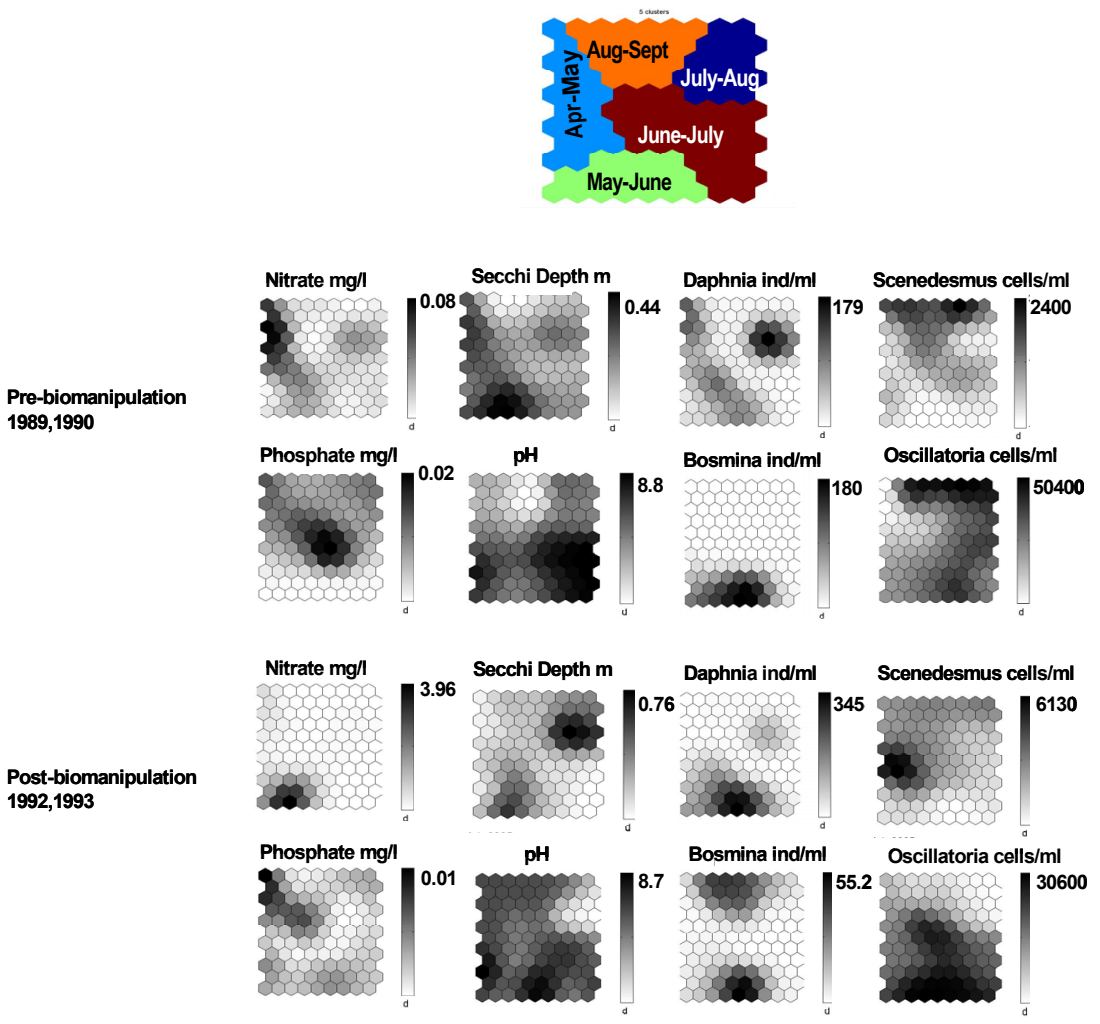

Figure 3: Nutrients, Secchi depths, phyto- and zooplankton distribution before and after biomanipulation in Lake Wolderwijd, patternised by NSANN. 
April to May. This change in seasonality of phyto- and zooplankton indicates a complex interrelationship, involving successional dynamics of competition between Oscillatoria and Scenedesmus and also predation i.e. grazing of phytoplankton by zooplankton during the same period. There are two plausible explanations; (1) grazing as there is a decrease in the abundance of green and other grazeable algae during the clear-water phase in May-June (spring peak) (2) nutrient limitations with summer blooms of algae. Our results suggest that phytoand zooplankton communities in Lake Wolderwijd are regulated by both grazing and nutrients, but the relative strengths vary seasonally.

In spring during the clear-water periods, grazing overwhelms nutrients but in summer, nutrient may limit the phytoplankton communities, similar to the results of a study on Lake Mendota (Vanni and Tempte [18]). According to Reynolds [19], phytoplankton is grazed by zooplankton. Daphnia and Bosmina populations have high filtering capacities that can be exploited for practical biomanipulation. Clear-water phase usually occur in spring in eutrophic lakes during May to June (Sommer et al. [20]), with low phytoplankton abundances. According to Crowder et al. [6]), variation in intensity of spring mixing in lakes yields different initial nutrient conditions. Seasonal algal succession can begin with different species composition and it has been shown that N: P shifts can lead to competitive shifts in phytoplankton community composition which may be differentially useful to zooplankton grazers (Crowder et al. [6]). Filamentous Oscillatoria are however less favourable food source for zooplankton (Gliciwz [21]).

Competition for food sources is postulated to affect the seasonality between the zooplankton as before biomanipulation, Daphnia was most abundant in July-August while Bosmina was highest in the months of May to June. After biomanipulation, Daphnia shifted to an abundance in May to June period i.e. concurrent with Bosmina peaks. There are also small clusters indicating an increasing abundance of Bosmina from August to September, evidence of niche differentiation. The seasonal fluctuations between the two periods, attest to the complexity of the phyto-zooplankton interactions in Lake Wolderwijd. The dynamics involve changes in nutrient limitations as a result of ongoing flushing, fine tuned by increased grazing due to biomanipulation

\subsection{Phyto- and zooplankton functional group dynamics}

The hypotheses tested are that phyto- and zooplankton functional groups exhibit short-term seasonal patterns that relate to nutrients, $\mathrm{pH}$ and Secchi depths, with higher $\mathrm{pH}$, decreased light attenuation and higher abundances of edible phytoplankton before fish removal compared to lowered $\mathrm{pH}$, increased light attenuation and increased zooplankton grazing as a result of fish removal. The NSANN results are as shown in Figure 4. In the pre-biomanipulation period there is a distinct seasonal pattern between the abundances of blue-green algae (from July to September) with green algae being dominant in the August to September and diatoms from April to May. The zooplankton showed that 
Pre-biomanipulation 1989,1990

Post-biomanipulation 1992,1993
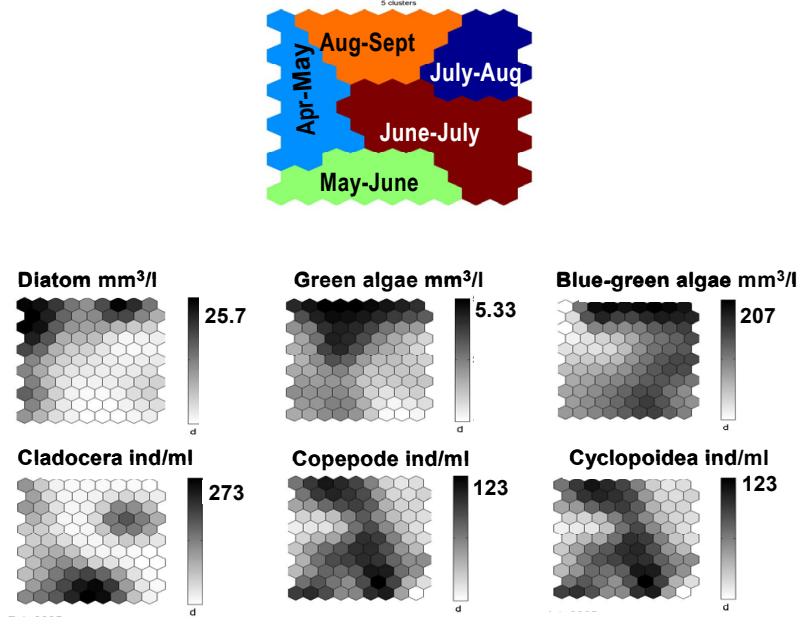

Cladocera ind $/ \mathrm{ml}$

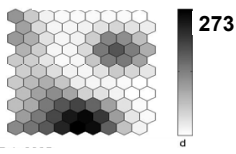

273

Cyclopoidea ind $/ \mathrm{ml}$
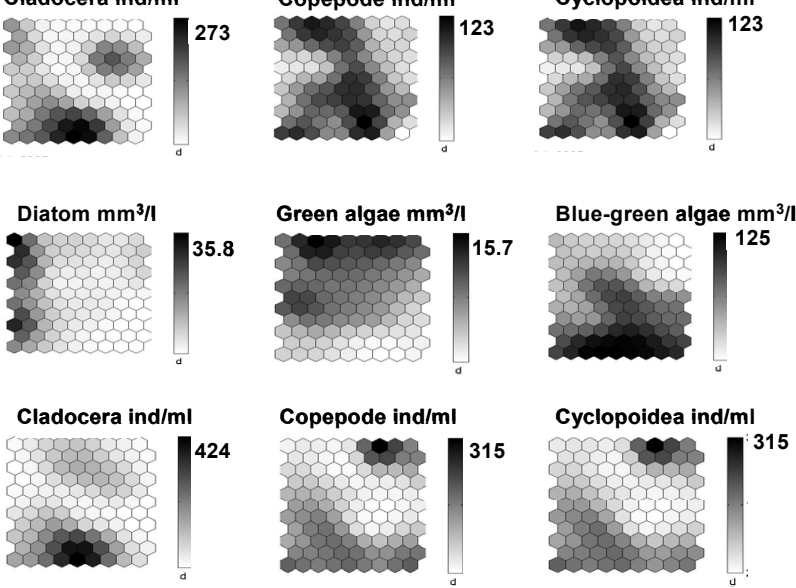

Figure 4: $\quad$ Functional groups of phyto- and zooplankton distribution before and after biomanipulation in Lake Wolderwijd patternised by NSANN.

Cladocera were abundant in May to June whereas the copepods that are made up of mostly Cyclopoidea were abundant in two phases; August to September and May to June.

There is a shift in the seasonal patterns after biomanipulation with blue-green algae being mostly dominant in May to June while copepods were shifted to July to August. Diatom however remained abundant in April to May and green algae were maximal in August to September. Cladocera remained abundant in May to June whereas Copepode/Cyclopoidea is maximal during July to August. Zooplankton biomass decreased in summer because of the shift in food supply. Significant top-down effects on phytoplankton, after the spring bloom, in the "clear-water phase" have been reported for cladoceran Daphnia spp in lakes (Sommer et al. [22]; Sommer et al. [20]). Overall, the NSANN recognised patterns related to seasonal succession with an increase in the cladocerans, followed by the copepods, also in relation to significant changes of the algae groups. 


\section{Conclusions}

NSANN can be a useful tool for pattern recognition in complex ecological timeseries data. The results have shown that changes in the top of the food-chain have had significant repercussions in the lower trophic levels. Distinct patterns were revealed in terms of seasonality and succession, $\mathrm{pH}$ tolerance as well as changes to phosphate and underwater light limitations of: (1) phytoplankton functional groups, Oscillatoria agardhii and Scenedesmus, (2) zooplankton functional groups, Daphnia and Bosmina dynamics and (3) as Daphnia increased with fish removal, Oscillatoria agardhii decreased, while green algae and diatom increase in abundance. Water clarity improved considerably in spring 1992 (May-June); the increases and decreases in phyto-zooplankton abundance tracking presumably that of the decreasing bream, as a result of fish removal, along with intensified flushing during that period.

\section{Acknowledgements}

This project is funded by the Universiti Sains Malaysia, in collaboration with The University of Adelaide using datasets from the Institute of Inland Water Management, Lelystad, The Netherlands, courtesy of Dr Diederik Van der Molen.

\section{References}

[1] Carpenter, S.R., Kitchell, J.F., and Hodgson, D.R., Cascading trophic interactions and lake productivity. Bioscience 35, pp 634-639, 1985.

[2] Jeppesen, E., Sondergaard, M., Mortensen, E., Kristensen, P., Riemann, B., and Jensen, H.J., Fish manipulation as a lake restoration tool in shallow, eutrophic temperate lakes 1: cross-analysis of three Danish case-studies. Hydrobiologia 200/201, pp 205-218, 1990.

[3] Moss, B., Stansfield, J., Irvine, K., Perrow, M., and Phillips, G., Progressive restoration of a shallow lake - a twelve year experiment in isolation, sediment removal and biomanipulation. Journal of Applied Ecology 33 (1). pp 71-86, 1996.

[4] Hosper H.S., (ed). Stable states, buffers and switches: An ecosystem approach to the restoration and management of shallow lakes in the Netherlands, 37, 1998.

[5] Benndorf, J., Possibilities and limits of controlling eutrophication by biomanipulation. Int Revue Ges Hydrobiol, 80, pp 519-534, 1995.

[6] Crowder, L.B., Drenner, R.W., Kerfoot, W.C., McQueen, D.J., Mills, E.L., Sommer, U., Spencer, C.N., Vanni, M.J., Food web interactions in lakes. In Complex Interactions in Lake Communities. Carpenter, S.R. (ed): National Science Foundation, pp. 141-161, 1988.

[7] Jeppesen, E., Jensen, J.P., Sondergaard, M., Lauridsen, T.L., Pedersen, L.J., and Jensen, L., Top-down control in freshwater lakes with special emphasis 
on the role of fish, submerged macrophytes and water depth. Hydrobiologia 342/343, pp 151-164, 1997.

[8] van der Molen, D.T., and Boers, P.C., Changes in phosphorus and nitrogen cycling following food web manipulations in a shallow Dutch lake. Freshwater Biology 35, pp 189-202, 1996.

[9] Gulati, R.D., and van Donk, E., Lakes in the Netherlands, their origin, eutrophication and restoration: state-of-the-art review. Hydrobiologia 478, pp 73-106, 2002.

[10] Recknagel F, Talib A, van der Molen, D.T., Phytoplankton Community Dynamics Of Two Adjacent Dutch Lakes In Response To Seasons And Eutrophication Control Unravelled By Non-Supervised Artificial Neural Networks. Ecological Informatics 1, pp 277-285, 2006.

[11] van der Molen D.T., The role of eutrophication models in water management. PhD, Wageningen University, The Netherlands, 1999.

[12] Kohonen, T., Self-Organization and Associative memory. Berlin: SpringerVerlag, 1989.

[13] Kohonen, T., (ed) Self-organizing maps. Heidelberg: Springer-Verlag. 1995.

[14] Vesanto J., SOM-Based Data Visualization Methods. Intelligent Data Analysis 3:111-126, 1999.

[15] Reynolds, C.S., (ed) The Ecology of Freshwater Phytoplankton:: Cambridge University Press. 1984.

[16] Paerl H.W., Nuisance phytoplankton blooms in coastal, estuarine, and inland waters. Limnol. Ocenogr. 33, pp 823-847, 1988.

[17] Shapiro, J., Blue green algae: Why they become dominant. Science, 179, pp 382-384, 1973.

[18] Vanni, M.J., and Tempte, J., Seasonal patterns of grazing and nutrient limitation of phytoplankton in a eutrophic lake. Limn.Oceanogr, 35(3): pp 697-709, 1990.

[19] Reynolds, C.S., The long, the short and the stalled: on the attributes of phytoplankton selected by physical mixing in lakes and rivers. Hydrobiologia, 289, pp 9-21, 1994.

[20] Sommer, U., Gilwicz, Z.M., Lampert, W., and Duncan, A., The PEG* model of seasonal succession of planktonic events in freshwaters. Arch.Hydrobiol 106, pp 433-471, 1986.

[21] Gliciwz, Z.M., Why do cladocerans fail to control algal blooms? Hydrobiologia 200/201, pp 83-98, 1990.

[22] Sommer, U., Sommer, F., Santer, B., Zollner, E., Jurgens, K., Jamieson, C., Boersma, M., and Gocke, K., Daphnia versus copepod impact on summer phytoplankton: functional compensation at both trophic levels. Oecologia, 135, pp 639-647, 2003. 